University of Nebraska - Lincoln

DigitalCommons@University of Nebraska - Lincoln

$7-2013$

\title{
Occupational Exposures to Respirable Crystalline Silica During Hydraulic Fracturing
}

\author{
Eric J. Esswein \\ National Institute for Occupational Safety and Health, eje1@cdc.gov \\ Michael Breitenstein \\ National Institute for Occupational Safety and Health \\ John Snawder \\ National Institute for Occupational Safety and Health \\ Max Kiefer \\ National Institute for Occupational Safety and Health \\ W. Karl Sieber \\ National Institute for Occupational Safety and Health
}

Follow this and additional works at: https://digitalcommons.unl.edu/publichealthresources

Esswein, Eric J.; Breitenstein, Michael; Snawder, John; Kiefer, Max; and Sieber, W. Karl, "Occupational Exposures to Respirable Crystalline Silica During Hydraulic Fracturing" (2013). Public Health Resources. 281.

https://digitalcommons.unl.edu/publichealthresources/281

This Article is brought to you for free and open access by the Public Health Resources at DigitalCommons@University of Nebraska - Lincoln. It has been accepted for inclusion in Public Health Resources by an authorized administrator of DigitalCommons@University of Nebraska - Lincoln. 


\title{
Occupational Exposures to Respirable Crystalline Silica During Hydraulic Fracturing
}

\author{
Eric J. Esswein, ${ }^{1}$ Michael Breitenstein, ${ }^{2}$ John Snawder, ${ }^{2}$ Max Kiefer, ${ }^{1}$ \\ and W. Karl Sieber ${ }^{3}$ \\ ${ }^{1}$ National Institute for Occupational Safety and Health, Western States Office, Denver, Colorado \\ ${ }^{2}$ National Institute for Occupational Safety and Health, Division of Applied Research and Technology, \\ Cincinnati, Ohio \\ ${ }^{3}$ National Institute for Occupational Safety and Health, Division of Surveillance, Hazard Evaluations and \\ Field Studies, Cincinnati, Ohio
}

This report describes a previously uncharacterized occupational health hazard: work crew exposures to respirable crystalline silica during hydraulic fracturing. Hydraulic fracturing involves high pressure injection of large volumes of water and sand, and smaller quantities of well treatment chemicals, into a gas or oil well to fracture shale or other rock formations, allowing more efficient recovery of hydrocarbons from a petroleum-bearing reservoir. Crystalline silica ("frac sand") is commonly used as a proppant to hold open cracks and fissures created by hydraulic pressure. Each stage of the process requires hundreds of thousands of pounds of quartzcontaining sand; millions of pounds may be needed for all zones of a well. Mechanical handling of frac sand creates respirable crystalline silica dust, a potential exposure hazard for workers. Researchers at the National Institute for Occupational Safety and Health collected 111 personal breathing zone samples at 11 sites in five states to evaluate worker exposures to respirable crystalline silica during hydraulic fracturing. At each of the 11 sites, full-shift samples exceeded occupational health criteria (e.g., the Occupational Safety and Health Administration calculated permissible exposure limit, the NIOSH recommended exposure limit, or the ACGIH threshold limit value), in some cases, by 10 or more times the occupational health criteria. Based on these evaluations, an occupational health hazard was determined to exist for workplace exposures to crystalline silica. Seven points of dust generation were identified, including sand handling machinery and dust generated from the work site itself. Recommendations to control exposures include product substitution (when feasible), engineering controls or modifications to sand handling machinery, administrative controls, and use of personal protective equipment. To our knowledge, this represents the first systematic study of work crew exposures to crystalline silica during hydraulic fracturing. Companies that conduct hydraulic fracturing using silica sand should evaluate their operations to determine the potential for worker exposure to respirable crystalline silica and implement controls as necessary to protect workers.

[Supplementary materials are available for this article. Go to the publisher's online edition of Journal of Occupational and Environmental Hygiene for the following free supplemental resource: a file containing controls and recommendations to limit worker exposures to respirable crystalline silica at hydraulic fracturing work sites.]

Keywords completions operations, crystalline silica, hydraulic fracturing, oil and gas extraction, sand

Correspondence to: Eric J. Esswein, National Institute for Occupational Safety and Health, Western States Office, Denver Federal Center, P.O. Box 25226, Denver, CO 80225; e-mail: eje1 @ cdc.gov.

\section{INTRODUCTION}

$\mathrm{O}$ ccupational exposure to respirable crystalline silica is a well-established hazard in mining, sandblasting, foundry work, agriculture, and construction, but not for oil and gas extraction work, which includes hydraulic fracturing. ${ }^{(1-9)} \mathrm{Hy}-$ draulic fracturing involves high pressure injection of large volumes of water $(\approx 95 \%$ of total volume) "proppant" $(\approx 4.5 \%$, typically as silica sand) and lesser quantities $(\leq 1.0 \%)$ of treatment chemicals (commonly a combination of surfactants, acids, scale inhibitor, clay stabilizers, corrosion/precipitation inhibitors, $\mathrm{pH}$ adjusting agents, gels, gel breakers, and biocides) into hydrocarbon-bearing strata to enhance recovery of oil and gas, particularly from deep shale formations. Hydraulic fracturing creates and enhances cracks and fissures in the geology; proppant holds the fractures open, allowing more efficient and sustained flow back of gas or oil.

Also called "well stimulation," "pressure pumping," or "completions operations," hydraulic fracturing has been used since the 1940s and has increased substantially over the last 10 years with the advent of "unconventional" drilling techniques (e.g., directional and horizontal) to access oil and gas not previously feasible with vertical drilling techniques alone. 
Although silica sand is the most commonly used proppant, aluminum pellets, sintered bauxite, man-made ceramics, and resin-coated sand can also be used depending on geological conditions. ${ }^{(10,11)}$

Onshore oil and gas extraction (well drilling, servicing, and hydraulic fracturing) falls within the jurisdiction of the Occupational Safety and Health Administration (OSHA). Workplace safety hazards (e.g., risks for fatal injuries) in the upstream oil and gas extraction industry are documented, but to our knowledge, there are few (if any) published studies of chemical exposure risks for land-based crews during hydraulic fracturing operations. ${ }^{(12,13)}$ Occupational health knowledge gaps in completions operations (i.e., hydraulic fracturing) include (1) understanding which job titles have risks for chemical exposures; (2) quantifying the magnitude of exposure risks (if present) for both chemicals and minerals; and (3) understanding the relative contribution of all likely route(s) of exposure, including inhalation, dermal exposures, and ingestion.

Approximately 435,000 workers were employed in the U.S. oil and gas extraction industry in 2010, nearly half employed by well servicing companies, including companies that conduct hydraulic fracturing. ${ }^{(14)}$ To evaluate possible occupational health hazards, NIOSH initiated the Field Effort to Assess Chemical Exposures in Oil and Gas Extraction Workers in 2010. The work began with observations of completions work sites; reviews of safety data sheets; and discussions with work crews, supervisors, and health and safety personnel at hydraulic fracturing sites. ${ }^{(15)}$ To date, exposure assessments for respirable crystalline silica during hydraulic fracturing have been the predominant focus of the NIOSH field effort.

\section{Crews and Machinery}

At a typical site, 10-12 Driver/Operators position and set up equipment, configure and connect piping, pressure test, then operate the equipment (e.g., sand movers, blender, and chemical trucks) required for hydraulic fracturing. Other employees operate water tanks and water transport systems, and several control on-site traffic, including sand delivery trucks and other vehicles. An additional crew includes Wire Line (typically 3-5) who configure and assemble well casing perforation tools and operate cranes to move tools and equipment into and out of the well. Operators run the diesel-driven pump trucks necessary for hydraulic fracturing and operate sand movers and blender trucks to distribute and mix proppant (e.g., sand) and liquids. Chemical Truck Operators monitor and manage delivery of the necessary well treatment additives to the blender trucks for delivery to the well. Operationally, the entire process is monitored and controlled by personnel in onsite data vehicles with real-time monitoring of aboveground and in-well parameters, including temperatures, pressures, and flow rates of liquids and proppant.

On a typical 12-hr shift, workers may operate a specific piece of machinery (e.g., sand mover, blender truck) or may operate different machines over a shift. Roving Operators,
Water Tank Operators, and Sand Coordinators/Ground Guides often work in different locations over a shift.

\section{Sand Use, Transport, and Delivery in Modern, Unconventional Oil and Gas Extraction}

A typical unconventional gas or oil well has 12-20 stages (also called zones) that are fractured; some wells can have 40 or more stages. As stages increase, more water and proppant are required. Moving proppant along transfer belts, pneumatically filling and operating sand movers, involves displacement of hundreds of thousands of pounds of sand per stage, which creates airborne dusts at the work site.

Proppant (e.g., sand) is delivered to the well site by sand trucks (e.g., dry-bulk tractor trailers). Depending on the number of stages to be completed, delivery may consist of a single sand transfer or require serial proppant deliveries throughout the day. Sand trucks are offloaded by the Driver/Operator who connects the delivery truck to a sand holding/sand transport vehicle, hereafter called "sand mover," that uses compressed air to pump sand through fill ports on sides of sand movers; offloading takes 30 to $45 \mathrm{~min}$.

Sand movers supply sand to blender trucks via a motordriven belt assembly located beneath the mover. The assembly retracts and extends, elevates, and swings and is commonly referred to as the "dragon tail." Sand Mover Operator stations are located on top rear and side rear of the mover directly above and to the side of the dragon tail. Larger proppant loads are increasingly common, requiring multiple sand movers and a transfer or "T-belt" to convey sand between the sand mover and the blender truck. Sand Mover Operators control sand delivery by hydraulically controlling gates on the bottom of the sand mover and by manipulation of belt speed. Sand Mover Operators observe proppant being delivered into the blender hopper (or onto the T-belt) and communicate with Blender Operators and personnel in data monitoring vehicles. The intent is for the proppant to remain dry until it enters the wet section of the blender before pumping through a manifold, connection piping, and into the wellbore.

Despite differences in shape, size, color, and quality, all sand used for hydraulic fracturing consists of silicon, the second most abundant element in the earth's crust. ${ }^{(16)}$ The most common crystalline form of silicon dioxide $\left(\mathrm{SiO}_{2}\right)$ is quartz. ${ }^{(16)}$ Various types, sizes, colors, and treatments (e.g., Northern white; Texas yellow; 20/40, 40/70, and 100 mesh; plain vs. resin coated) of silica sand (typically $99 \%$ quartz) are used as the primary proppant for completions operations across the United States. Increased use and demand for silica sand proppant is expected to continue with ongoing completion operations in existing oil and gas basins and as operations increase across relatively newer, developing areas (e.g., Bakken formation in North Dakota and Niobrara in Northeast Colorado and parts of Kansas and Nebraska). ${ }^{(17)}$ High-quality frac sand is typically defined as having consistent shape (sphericity), size, and compressive strength. The American Petroleum Institute (API) has developed specifications/standards (RP 56) for certain mesh sizes of frac sand. ${ }^{(18)}$ 


\section{Silica-Related Disease}

Inhalation of respirable crystalline silica can cause silicosis, lung cancer, autoimmune disorders, kidney disease, and an increased risk of tuberculosis. ${ }^{(19-24)}$ Although U.S. mortality statistics typically undercount silicosis cases, death certificates document that between 2000 and 2005 an average of 162 annual deaths from all occupations described silicosis as the proximal cause or a prevailing condition. ${ }^{(25,26)}$

The NIOSH recommended exposure limit (REL) for respirable crystalline silica is 0.05 milligrams of respirable silica per cubic meter of air $\left(\mathrm{mg} / \mathrm{m}^{3}\right)$ as a time-weighted average (TWA) for up to a 10-hr day to reduce the risk of developing silicosis, lung cancer and other adverse health effects. ${ }^{(27)}$ The $\mathrm{ACGIH}^{\circledR}$ threshold limit value $\left(\mathrm{TLV}^{\circledR}\right)$ for respirable silica (as $\alpha$ quartz) is $0.025 \mathrm{mg} / \mathrm{m}^{3}$ TWA for up to an 8 -hr workday. ${ }^{(28)}$ The OSHA permissible exposure limit (PEL) for respirable dust containing silica in general industry is inversely weighted by the proportion of silica in the sampled dust and determined by the formula: $10 \mathrm{mg} / \mathrm{m}^{3} \div(\% \text { silica }+2)^{\left({ }^{(29)}\right.}$ For comparisons to the OSHA criterion, a PEL is calculated for each sample. Assuming 100\% silica, the calculated PEL would be $\approx 0.10 \mathrm{mg} / \mathrm{m}^{3}$ as an 8 -hr TWA. NIOSH recommends minimizing risks for silica exposures to workers exposed at or above the REL by substituting less hazardous materials, using engineering controls to limit exposures, and, if engineering controls cannot control exposures $<$ REL, using respiratory protection and making medical examinations available to exposed workers. ${ }^{(23)}$

\section{METHODS}

E xposure assessments for respirable crystalline silica were conducted for three consecutive days at 11 well sites in five states (Colorado, Texas, North Dakota, Arkansas, and Pennsylvania) from August 2010 through September 2011. Workers from 15 different job titles voluntarily participated. The purpose of the NIOSH field effort was explained to management and employees prior to sample collection; personal breathing zone (PBZ) samples were collected only on employees who agreed to participate. Workers participating on the first day were asked to participate on the two successive days of sampling, but sequential participation was not consistent at every site. After each day of sampling, NIOSH researchers discussed activities with employees and management to verify that samples were collected during typical hydraulic fracturing operations.

Full-shift (typically $12 \mathrm{hr}$ ) PBZ samples for respirable particulates and silica were simultaneously collected using AirChek XR 5000 (SKC Inc., Eighty Four, Pa.) personal sampling pumps connected to pre-weighed, 5- $\mu \mathrm{m}$ polyvinyl chloride filters in three-piece, 37-mm polystyrene sampling cassettes (Omega Specialty Division, SKC Inc.). The respirable fractions of dust were captured using BGI model GK2.69 cyclones (BGI Incorporated, Waltham, Mass.). ${ }^{(30)}$ Sampling trains were calibrated in-line to the BGI recommended flow rate for respirable particulates at $4.2 \mathrm{~L} / \mathrm{min}$ and post-calibrated with Dry Cal Defender 530 calibrators (Bios International, Butler Park, N.J.). Cyclones and cassettes were located in the worker's PBZ.

Kestrel model 4500 portable weather stations (Weather Republic, LLC, Downingtown, Pa.) were used to periodically measure temperature, relative humidity, and wind speed. Additional meteorological data were obtained from an on-line reporting service.

All samples were analyzed at an AIHA $^{\circledR}$-accredited laboratory, according to the NIOSH Manual of Analytical Methods (NMAM) method 0600, for gravimetric analysis of total particulates and NMAM method 7500, X-ray diffraction analysis for crystalline silica (as quartz, cristobalite, and tridymite). ${ }^{(31,32)}$ For comparisons to the ACGIH TLV-TWA of $0.025 \mathrm{mg} / \mathrm{m}^{3}$ and the NIOSH REL of $0.05 \mathrm{mg} / \mathrm{m}^{3}$ as a TWA, calculations were made for the respirable fraction of silica alone. Numeric values reported by the laboratory for sample results between the limit of detection (LOD) and the limit of quantification (LOQ) were included in the statistical analysis of the data. If the respirable silica value was below the LOD, it was replaced by a value equal to the analytical LOD divided by the square root of 2, as described by Hornung and Reed. ${ }^{(33)}$ Four samples for respirable quartz were below the LOD and included workers with job titles of Pump Truck Operator, QC Tech, and Wireline Operator.

To calculate TWA concentrations for the OSHA PEL for respirable dust containing $>1 \%$ silica, percentage silica in the sample was determined by dividing the quartz results for each sample by amount of respirable dust and multiplying by 100 . A PEL was calculated for each sample using the formula for general industry: $10 \mathrm{mg} / \mathrm{m}^{3} \div(\%$ silica +2$) .{ }^{(29)}$ PELs were not calculated for four samples where percentage quartz could not be determined because the respirable dust fraction was $<$ the LOD. Sample results are expressed for the full work shift (typically $12 \mathrm{hr}$ ); they were not adjusted for exposures exceeding the 8-hr OSHA or TLV criteria or the 8- to 10-hr REL.

Exposure severities were calculated by dividing the exposure TWA by the occupational exposure limit (PEL, REL) and expressed as a value greater or less than unity. Severities greater than unity exceed the respective exposure criterion. To compare and express the magnitude of work crew exposures in relation to a calculated PEL or REL, severity means, geometric means (GM), standard deviations, and minimum, maximum, and median values were calculated for the 15 job titles in units of $\mathrm{mg} / \mathrm{m}^{3}$

A one-way analysis of variance was performed to evaluate for statistical differences in mean exposures among job titles with five or more samples (e.g., Blender Operators, Hydration Unit Operators, Sand Coordinators, Sand Mover Operators, T-belt Operators, and Water Tank Operators). Statistical differences between individual job title means were determined using the least significant difference (LSD) multiple comparison test (significance level, $\mathrm{p}=0.05$ ). The LSD can be seen as a t-test for differences between two means using a pooled error variance. ${ }^{(34)}$ Analysis of variance and LSD statistical tests were also used for overall comparisons between the different 
work sites and for measured concentrations of respirable dust containing silica. All calculations were performed using SAS version 9.2 (SAS Institute Inc., Cary, N.C.).

\section{RESULTS}

$\mathrm{T}$ he 11 locations included geographic, topographic, climatic, altitude, and environmental diversity. Site locations included the Eagle Ford shale play in the southwest Texas desert during the summer. Two sites were in the temperate, humid deciduous forests of the Marcellus and Fayetteville shale plays of Pennsylvania and Arkansas in the spring. Seven well sites were on the arid high plains of the Denver-Julesburg (DJ) basin in Colorado in late winter and summer; one site was on the northern plains of the Bakken formation in North Dakota during late summer. Elevations ranged from approximately 300 feet to slightly more than 5000 feet above sea level.

The exposure assessments occurred at single- and multiwell site locations during single and multiple-stage completions. Typically, two or three stages were completed in a shift. The DJ Basin 1 sites in Colorado involved refracturing one zone of two different wells each day over three consecutive days, for a total of six different well locations. With the exception of the Bakken site where approximately $60 \%$ of the proppant was Black Cat (a ceramic material), silica sand was the proppant used at the other locations and included 20/40, 40/70, and 100 mesh sieve sizes. At some sites, a proportion of the total proppant load included resin-coated sand, but proportions, usage time, and volumes were not available.

\section{Weather}

Meteorological conditions (average daily temperature and average daily low and high temperatures, sky conditions, precipitation, and wind speed) at the 11 sites are reported in Table I. Weather (wind, rain, or temperature) was never a limiting factor for site work. When it rained, rain was present for short periods, never interfering with sampling or completions operations. With exception of early to mid-morning periods, winds were typically measurable and varied, sometimes changing direction during the shift. Based on averages for the days the evaluations occurred, wind speed was in a range of 1.1-13 miles per hour (mph) at the sites. Average wind velocity and high wind was less (in a range of 1.1-5.4, and $10 \mathrm{mph}$, respectively) for the site on the Marcellus Shale in Pennsylvania.

\section{Personal Breathing Zone Sampling Results}

Quartz was the only silicate mineral detected; the median value was 53\% and samples ranged from < LOD to $100 \%$ quartz. Figure 1 describes silica concentrations in four discrete quantiles of 90th, 75th, 50th, and 25th percentiles. At the 90th percentile, 100 samples were determined to have up to $88 \%$ or less quartz.

Distribution of airborne particulates were evaluated and determined to follow a lognormal distribution using the ShapiroWilk test for goodness-of-fit and normality plots. ${ }^{(35,36)} \mathrm{Log}$ arithms of measured concentrations of respirable silica were used to calculate GM and standard deviations (SD) and for all statistical tests.

Table II lists 15 job titles, number of samples for each job title, the GM and geometric standard deviation (GSD) for respirable quartz in $\mathrm{mg} / \mathrm{m}^{3}$, and minimum, maximum, and median values expressed as TWAs. Geometric means and $95 \%$ confidence intervals for respirable silica concentrations for job titles having five or more samples are presented in Figure 2. Job titles with the highest GM exposures included T-belt and Sand Mover Operators (0.327 and 0.259); workers with lower GMs included Hydration Unit and Blender Operators (0.072 and 0.091); workers with the lowest GM exposures included Sand Coordinators and Water Tank Operators (0.054 and 0.048).

After exclusion of an obvious outlier for a T-belt Operator, no statistical differences were determined for exposures to respirable dust containing silica between Sand Mover Operators and T-belt Operators. Statistically significant differences $(\mathrm{p} \leq 0.05)$ were found between T-belt Operators compared with Sand Coordinators and Water Tank Operators and also between Sand Mover Operators and Hydration Unit Operators, Blender Operators, Sand Coordinators, and Water Tank Operators. For respirable silica alone, no statistical differences were found between Sand Mover Operators and T-belt Operators but significant differences $(\mathrm{p} \leq 0.05)$ were found between Sand Mover Operators and Hydration Unit Operators, Blender Operators, Sand Coordinators, and Water Tank Operators.

Table III lists the numbers and percentages of samples collected for each of the job titles that exceeded the ACGIH TLV, the NIOSH REL, or a calculated OSHA PEL. Figure 3 shows the comparisons for arithmetic means of respirable

TABLE I. Meteorological Data at Six Shale Play Locations, 2010-2011

\begin{tabular}{llcccccccc}
\hline Location & Season & $\begin{array}{c}{ }^{\circ} \mathbf{F} \\
\text { Avg. }\end{array}$ & $\begin{array}{c}{ }^{\circ} \mathbf{F} \\
\text { Low }\end{array}$ & $\begin{array}{c}{ }^{\circ} \mathbf{F} \\
\text { High }\end{array}$ & \multicolumn{1}{c}{ Sky } & $\begin{array}{c}\text { Precip. } \\
\text { (inches) }\end{array}$ & $\begin{array}{c}\text { Wind Speed Avg. } \\
\text { Range (mph) }\end{array}$ & $\begin{array}{c}\text { Wind Speed } \\
\text { High (mph) }\end{array}$ \\
\hline Eagle Ford, Texas & Summer & 87 & 75 & 101 & Clear & 0 & $8-11$ & $14-15$ \\
DJ Basin \#1, Colo. & Winter & 49 & 38 & 71 & Clear-partly cloudy & 0 & $1.2-10$ & $15-17$ \\
Fayetteville, Ark. & Spring & 62 & 53 & 75 & Cloudy & $0.83(0-1.5)$ & $7-10$ & $11-12$ \\
Marcellus, Pa. & Spring & 74 & 63 & 92 & Cloudy-partly cloudy & 0.22 & $1.1-5.4$ & 10 \\
DJ Basin \#2, Colo. & Summer & 70 & 58 & 91 & Clear-partly cloudy & 0.05 & $10-13$ & $15-16$ \\
Bakken, N.D. & Summer & 68 & 56 & 89 & Clear-partly cloudy & $0.22-0.5$ & $7-12$ & $11-35$ \\
\hline
\end{tabular}




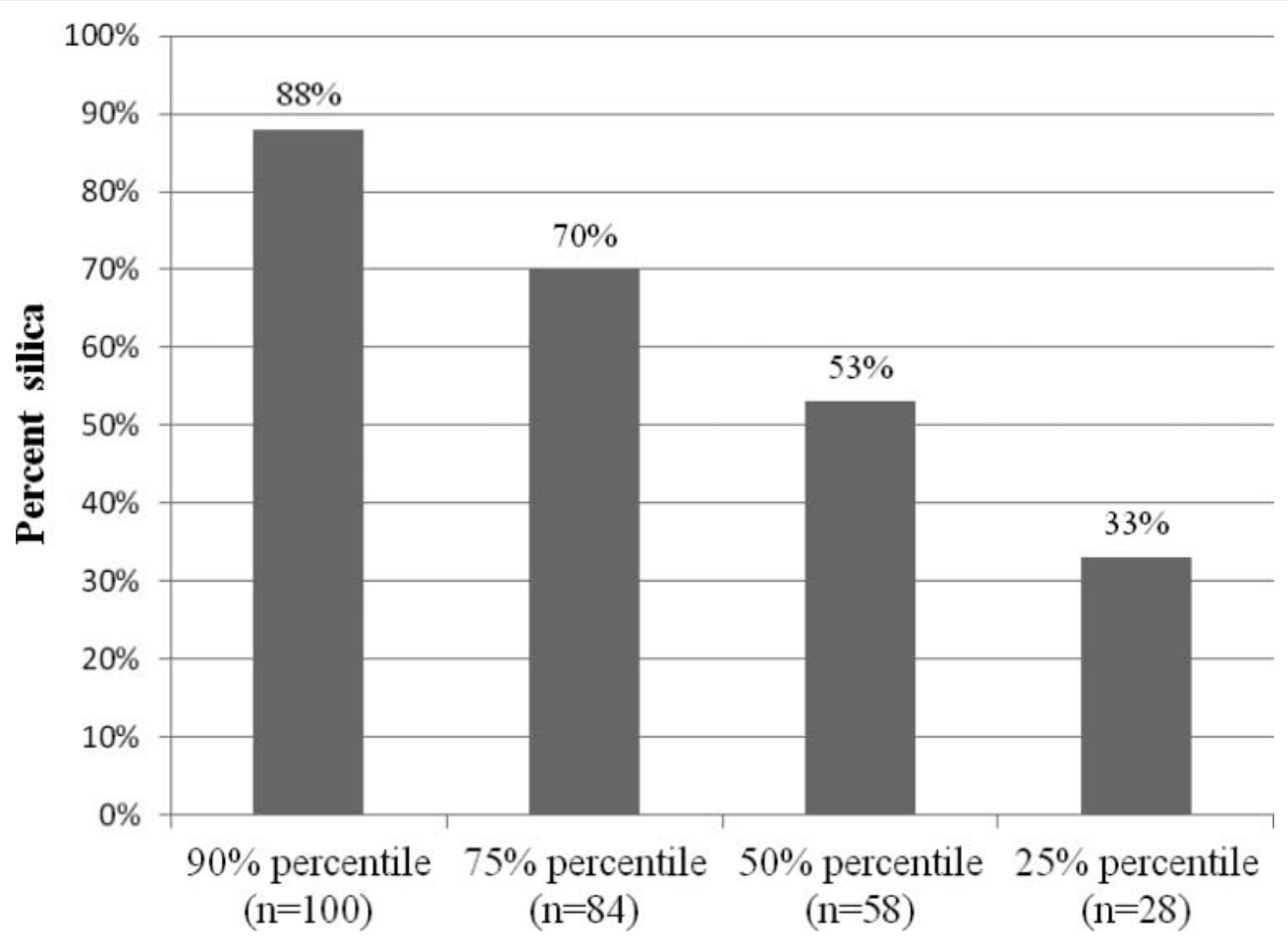

FIGURE 1. Quantiles, distribution of percent silica in PBZ samples $(n=111)$.

silica TWAs $\left(\mathrm{mg} / \mathrm{m}^{3}\right)$ for job titles with five or more samples and a calculated OSHA PEL used for comparison purposes in this figure based the median value of 53\% silica content in the 111 samples, and the NIOSH REL value.

To compare and express the magnitude of work crew exposures in relation to OSHA PELs for respirable dust containing silica and the NIOSH REL for respirable silica alone, means of job title severities were calculated and are listed in Tables IV and V for the NIOSH REL or the OSHA PEL, respectively. Arithmetic standard deviations (ASD), minimum, maximum, and median values are also listed as these can be used for direct comparisons to occupational exposure criteria (PEL, REL and

TABLE II. PBZ Statistics by Job Title, Respirable Quartz TWA $\left(\mathrm{mg} / \mathrm{m}^{3}\right)$

\begin{tabular}{lcccccc}
\hline Job Title & No. of Samples & GM & GSD & Min TWA & Max TWA & Median TWA \\
\hline Blender Operator & 16 & 0.091 & 1.266 & 0.007 & 0.485 & 0.102 \\
Chemical Truck Operator & 3 & 0.121 & 1.828 & 0.040 & 0.319 & 0.139 \\
Fueler & 2 & 0.042 & 1.225 & 0.034 & 0.051 & 0.043 \\
Hydration Unit Operator & 5 & 0.072 & 2.209 & 0.009 & 0.746 & 0.044 \\
Mechanic & 3 & 0.052 & 1.511 & 0.023 & 0.088 & 0.069 \\
Operator, Data Van & 1 & 0.043 & - & 0.043 & 0.043 & 0.043 \\
Pump Truck Operator & 1 & 0.021 & - & 0.021 & 0.021 & 0.021 \\
QC Tech & 1 & 0.013 & - & 0.013 & 0.013 & 0.013 \\
Roving Operator & 4 & 0.019 & 1.628 & 0.006 & 0.059 & 0.020 \\
Sand Coordinator & 10 & 0.054 & 1.333 & 0.017 & 0.326 & 0.061 \\
Sand Truck Driver & 1 & 0.041 & - & 0.041 & 0.041 & 0.041 \\
Sand Mover Operator & 50 & 0.259 & 1.223 & 0.007 & 2.755 & 0.381 \\
T-belt Operator & 6 & 0.327 & 2.003 & 0.015 & 2.570 & 0.453 \\
Water Tank Operator & 7 & 0.048 & 1.339 & 0.019 & 0.136 & 0.056 \\
Wireline Operator & 1 & 0.007 & - & 0.007 & 0.007 & 0.007 \\
Totals & 11 & 0.122 & 1.152 & 0.006 & 2.755 & 0.109 \\
\hline
\end{tabular}

Notes: Titles followed by superscripts are significantly different $(\mathrm{p} \leq 0.05)$. Values not calculated for statistics where $\mathrm{N}=1$. 


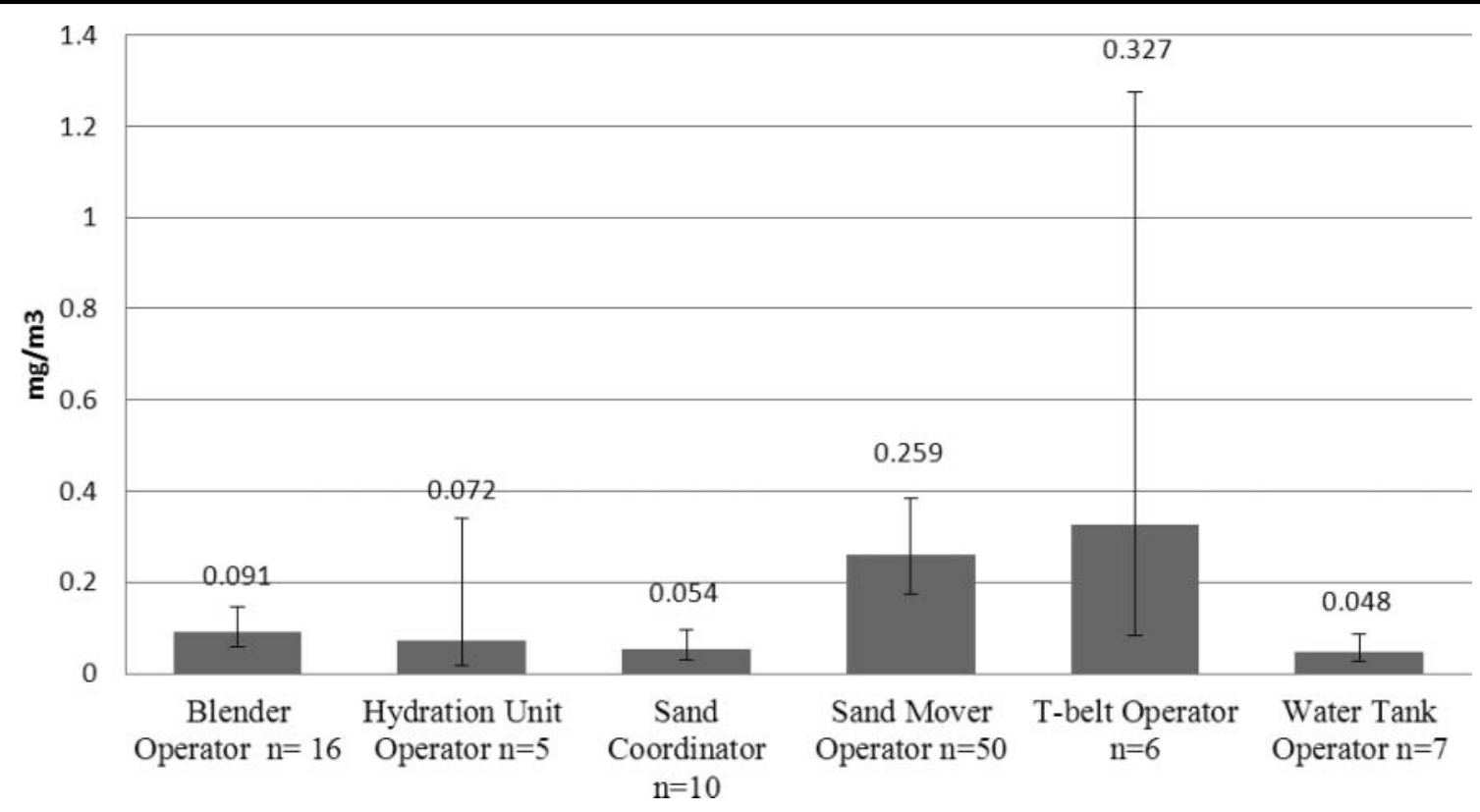

FIGURE 2. Respirable silica geometric means $\left(\mathrm{mg} / \mathrm{m}^{3}\right)$ and $95 \%$ confidence intervals for job titles with 5 or more samples

TLV). Job titles with the highest mean severities included Transfer Belt and Sand Mover Operators (mean severities of 14.55 and 10.44, respectively, based on the NIOSH REL). Job titles with lowest exposures (mean severities less than one, and for samples where $\mathrm{n}>1$ ) included Roving Operator (0.52) and Fueler (0.85) who worked in a variety of locations at the sites or spent only short periods of time in site areas when sand was being transported on site. Job titles with exposures greater than 10 times the NIOSH REL included Sand Mover Operator $(\mathrm{n}=19)$, Transfer Belt Operator $(\mathrm{n}=2)$, and Hydration Unit Operator $(\mathrm{n}=1)$.

\section{Personal Breathing Zone Respirable Silica by Job Site}

Statistically significant differences $(\mathrm{p} \leq 0.05)$ in overall concentrations of respirable silica were not found between the Eagle Ford, Fayetteville shale, DJ Basin 1 and 2 sites, and Marcellus shale formations; however, all these sites (except the Eagle Ford) did differ from the Bakken formation where ceramic was the primary proppant used at that site.

Table VI lists the sites, numbers of samples collected, and percentages that exceeded the TLV, REL, or the calculated PELs. Ninety three of $111(83.8 \%)$ of the samples exceeded the TLV, 76 (68.5\%) exceeded the REL, and 57

TABLE III. Samples Above ACGIH TLV, NIOSH REL, or OSHA PEL

\begin{tabular}{lcccc}
\hline Job Title & ACGIH TLV & NIOSH REL & OSHA PEL & No. of Samples \\
\hline Blender Operator & $15(93.8 \%)$ & $13(81.3 \%)$ & $8(50 \%)$ & 16 \\
Chemical Truck Operator & $3(100 \%)$ & $2(66.7 \%)$ & $2(66.7 \%)$ & 3 \\
Fueler & $2(100 \%)$ & 0 & 0 & 2 \\
Hydration Unit Operator & $4(80 \%)$ & $2(40 \%)$ & $2(40 \%)$ & 5 \\
Mechanic & $2(66.7 \%)$ & $2(66.7 \%)$ & 0 & 3 \\
Operator, Data Van & $1(100 \%)$ & 0 & 0 & 1 \\
Pump Truck Operator & 0 & 0 & 0 & 1 \\
QC Tech & 0 & 0 & 0 & 1 \\
Roving Operator & $2(50 \%)$ & $1(25 \%)$ & 0 & 4 \\
Sand Coordinator & $7(70 \%)$ & $5(50 \%)$ & $1(10 \%)$ & 10 \\
Sand Truck Driver & $1(100 \%)$ & 0 & 0 & 1 \\
Sand Mover Operator & $46(92 \%)$ & $42(84 \%)$ & $37(74 \%)$ & 50 \\
T-belt Operator & $5(83.3 \%)$ & $5(83.3 \%)$ & $5(83.3 \%)$ & 6 \\
Water Tank Operator & $5(71.7 \%)$ & $4(57.1 \%)$ & $2(28.6 \%)$ & 7 \\
Wireline Operator & 0 & 0 & 0 & 1 \\
Totals & $93(83.8 \%)$ & $76(68.5 \%)$ & $57(51.4 \%)$ & 111 \\
\hline
\end{tabular}




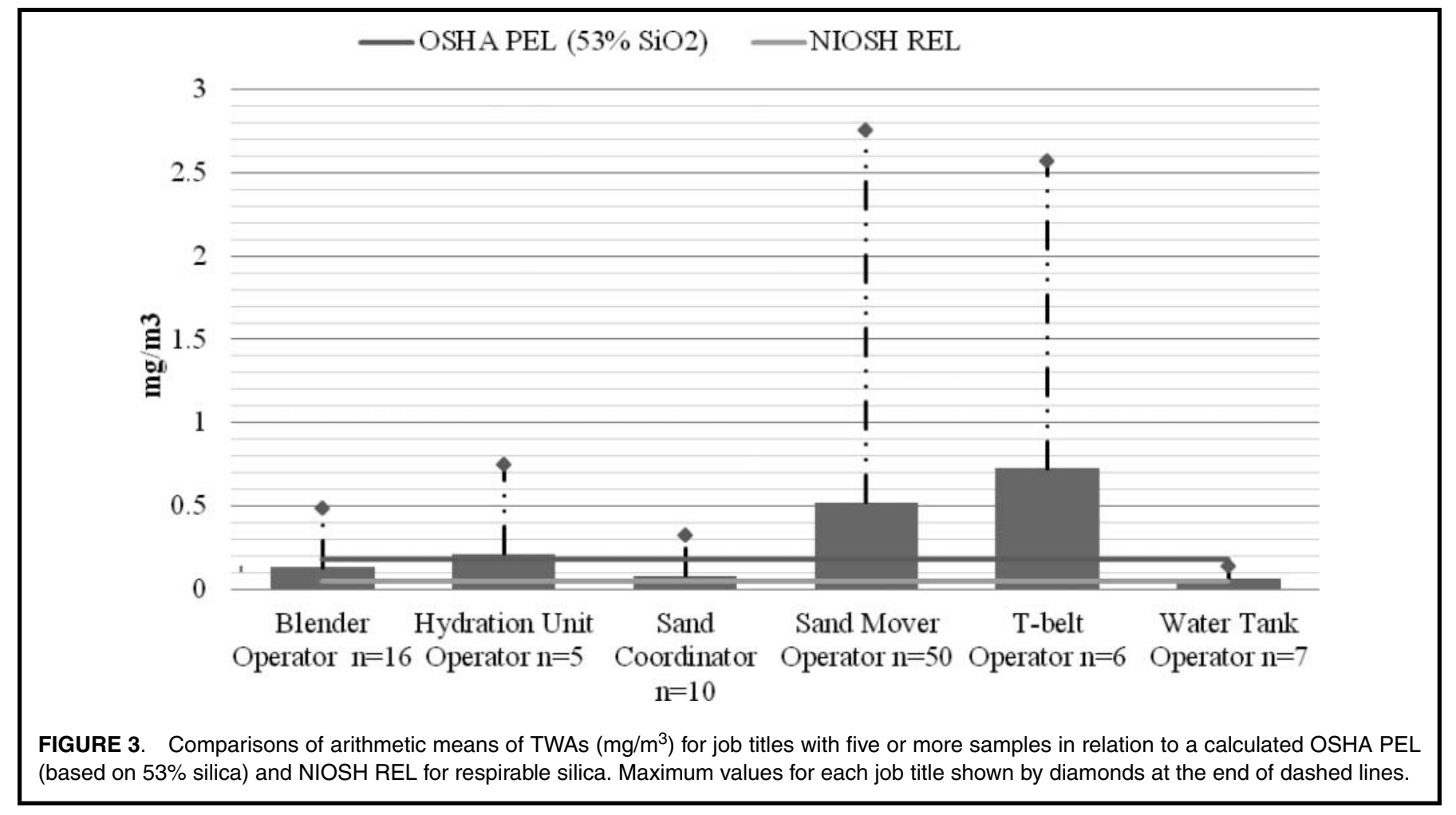

(51.4\%) exceeded a calculated PEL for respirable dust containing silica.

\section{Magnitude of Full-Shift Exposures to Respirable Crystalline Silica}

Silica exposures for some job titles exceeded the assigned protection factor of 10 for the half-mask, air-purifying respira- tors most commonly used at the locations. PBZ exposures exceeding a REL or PEL by a factor of 10 or more included Sand Mover Operators, $\mathrm{n}=19$ for the REL, $\mathrm{n}=8$ for the OSHA PEL, and T-belt Operators, and $\mathrm{n}=2$ and 1 for the REL and PEL, respectively. In some cases, exposures exceeded OELs by a factor greater than 20, including Sand Mover Operator $(n=7)$ and T-belt Operators $(n=1)$ for the

TABLE IV. PBZ NIOSH REL Mean Severities

\begin{tabular}{lcccccc}
\hline Job Title & No. of Samples & AM & ASD & Min & Max & Median \\
\hline Blender Operator & 16 & 2.58 & 0.59 & 0.14 & 9.70 & 2.03 \\
Chemical Truck Operator & 3 & 3.32 & 1.63 & 0.80 & 6.38 & 2.78 \\
Fueler & 2 & 0.85 & 0.17 & 0.68 & 1.02 & 0.85 \\
Hydration Unit Operator & 5 & 4.28 & 2.79 & 0.18 & 14.92 & 0.88 \\
Mechanic & 3 & 1.20 & 0.39 & 0.46 & 1.76 & 1.38 \\
Operator, Data Van & 1 & 0.86 & - & 0.86 & 0.86 & 0.86 \\
Pump Truck Operator & 1 & 0.42 & - & 0.42 & 0.42 & 0.42 \\
QC Tech & 1 & 0.26 & - & 0.26 & 0.26 & 0.26 \\
Roving Operator & 4 & 0.52 & 0.24 & 0.12 & 1.18 & 0.39 \\
Sand Coordinator & 10 & 1.60 & 0.57 & 0.34 & 6.52 & 1.22 \\
Sand Truck Driver & 1 & 0.82 & - & 0.82 & 0.82 & 0.82 \\
Sand Mover Operator & 50 & 10.44 & 1.59 & 0.14 & 55.10 & 7.62 \\
T-belt Operator & 6 & 14.55 & 7.57 & 0.30 & 51.40 & 9.06 \\
Water Tank Operator & 7 & 1.23 & 0.34 & 0.38 & 2.72 & 1.12 \\
Wireline Operator & 1 & 0.14 & - & 0.14 & 0.14 & 0.14 \\
Totals & 11 & 6.45 & 0.93 & 0.12 & 55.10 & 2.18 \\
\hline
\end{tabular}

Note: Values not calculated for samples where $\mathrm{n}=1$. 
TABLE V. PBZ OSHA PEL Mean Severities

\begin{tabular}{lcccccc}
\hline Job Title & No. of Samples & AM & ASD & Min & Max & Median \\
\hline Blender Operator & 16 & 1.34 & 0.30 & 0.09 & 4.93 & 1.08 \\
Chemical Truck Operator & 3 & 1.70 & 0.82 & 0.45 & 3.23 & 1.41 \\
Fueler & 1 & 0.57 & - & 0.57 & 0.57 & 0.57 \\
Hydration Unit Operator & 5 & 2.19 & 1.42 & 0.09 & 7.58 & 0.4 \\
Mechanic & 3 & 0.61 & 0.20 & 0.23 & 0.90 & 0.70 \\
Operator, Data Van & 1 & 0.49 & - & 0.49 & 0.49 & 0.49 \\
Pump Truck Operator & 0 & & & & & \\
QC Tech & 1 & 0.14 & - & 0.14 & 0.14 & 0.14 \\
Roving Operator & 4 & 0.25 & 0.09 & 0.08 & 0.50 & 0.21 \\
Sand Coordinator & 10 & 0.81 & 0.27 & 0.18 & 3.10 & 0.65 \\
Sand Truck Driver & 1 & 0.41 & - & 0.41 & 0.41 & 0.41 \\
Sand Mover Operator & 50 & 5.66 & 0.86 & 0.13 & 28.71 & 4.26 \\
T-belt Operator & 6 & 7.62 & 4.05 & 0.18 & 27.39 & 4.65 \\
Water Tank Operator & 7 & 0.63 & 0.17 & 0.21 & 1.36 & 0.54 \\
Wireline Operator & 1 & 0.07 & - & 0.07 & 0.07 & 0.07 \\
\hline
\end{tabular}

Note: Values not calculated for samples where $\mathrm{n}=1$.

NIOSH REL, and $n=3$ and $n=1$ for the same job titles for the OSHA calculated PEL. If the sampling results were adjusted for an extended work shift, that is, the difference between an 8-hr shift and a 12-hr work shift, the exposure severities would be $50 \%$ greater than those listed and described.

\section{DISCUSSION}

\section{Sources of Silica-Containing Dust Identified at the Work Sites}

Dust is visibly present during hydraulic fracturing especially when sand movers are refilled and actively operating, which is referred to as "hot loading." Workers closest to sand moving operations included T-belt and Sand Mover Operators (Figure 2), followed by Blender and Hydration Unit Operators. Direction and wind speed, as well as the configuration of the sand handling and other equipment on site, appear to influence the concentration, direction, and migration of airborne sand dusts. Predictably, when workers were near or downwind from point sources of dust generation they had greater risks for exposures than if farther away or upwind. At some sites, how equipment was configured and positioned created enclosed or restricted environments that may have limited natural dilution of airborne particulates and contributed to increased exposures to airborne dusts.

Workers less commonly observed in the immediate area of sand moving machinery included Sand Coordinators (Ground Guides), Water Tank Operators, and Chemical Truck Operators. However, in some cases, these job titles had exposures $>$ TLV, REL, or the PEL, indicating that PBZ exposures exceeding these concentrations can occur even when workers were not in proximity to the primary source(s) of dust generation. This could be due to silica-containing environmental dust carried onto the site or dusts generated from on-site vehicular traffic.

Blender, Chemical Truck, and Hydration Unit Operators worked in both closed and open cabs on their machinery, and these job titles had exposures that exceeded OELs even when Operators reported or were observed to spend most of the day in a cab. Blender trucks typically had enclosed cabs, but none had high-efficiency particulate filtration or positive pressurization. Respirable silica concentrations for workers in

TABLE VI. Samples Above ACGIH TLV, NIOSH REL, or OSHA PEL

\begin{tabular}{lcccc}
\hline Site & ACGIH TLV & NIOSH REL & OSHA PEL & Total No. Samples \\
\hline Fayetteville, Ark. & $24(92.3 \%)$ & $19(73.1 \%)$ & $14(53.9 \%)$ & 26 \\
DJ Basin 1, Colo. & $16(84.2 \%)$ & $14(73.7 \%)$ & $12(63.2 \%)$ & 19 \\
Eagle Ford, Texas & $5(62.5 \%)$ & $5(62.5 \%)$ & $4(50.0 \%)$ & 8 \\
DJ Basin 2, Colo. & $19(90.5 \%)$ & $14(66.7 \%)$ & $9(42.9 \%)$ & 21 \\
Marcellus, Pa. & $25(92.6 \%)$ & $23(85.2 \%)$ & $18(66.7 \%)$ & 27 \\
Bakken, N.D. & $4(40 \%)$ & $1(10 \%)$ & 0 & 10 \\
Totals & $93(83.8 \%)$ & $76(68.5 \%)$ & $57(51.4 \%)$ & 111 \\
\hline
\end{tabular}


vehicles having doors with tight-fitting seals and conditioned environments (e.g., data vans) did not exceed the TLV, REL, or PELs, with the exception of one Operator who spent time near sand moving equipment for a portion of the day.

Seven points of dust generation were consistent at each of the 11 work sites:

(1) Dust ejected from "thief hatches" on the tops of sand movers during filling. This source contributes to exposures to Sand Mover and Blender Operators and, depending on winds, may expose workers farther away, such as Water Tank Operators.

(2) Dusts released from the sand mover belt. This point source was observed to contribute to exposures to Sand Mover Operators, especially if the wind is strong and the Operator station is on the downwind side of the machine.

(3) Dust created at the blender hopper from the momentum of falling proppant below the dragon tail can contribute to exposure to Sand Mover and Blender Operators; the area below the dragon tail can be confined due to interacting machinery (Blender, Sand Movers, the T-belt), and depending on climatic conditions, there could also be a lack of natural ventilation.

(4) Dust released from T-belts when proppant is deposited onto the belt and conveyed to the blender. Sand impacting the belt as well as rotational and vibrational movement of the belt contributes to dust generation.

(5) Dust generated as proppant leaves the end of the dragon tail. This can be a secondary contributing source for both Blender Operators (i.e., cab-based operator and the hopper-based operator or other downwind work crews).

(6) Dust ejected from fill ports of sand movers during refilling operations. An absence of caps on the fill ports contributes to silica exposures of Sand Mover Operators, Blender Operators, and Sand Truck Drivers.

(7) Dust generated by site traffic, including frictional forces from truck tires, vehicle momentum, and release of air pressure from pneumatic brakes, contributes to exposures to Sand Coordinators and Sand Truck Drivers. Dust blown onto the work site from off-site sources was also observed on several occasions and may be a small and variable contributor to work crew exposures.

\section{CONCLUSION}

7 ull-shift, PBZ exposures to respirable crystalline silica is 1 an occupational exposure hazard for workers at hydraulic fracturing sites. Quartz was the only silicate mineral identified; median percentage quartz in the $111 \mathrm{PBZ}$ samples was $53 \%$. Workplace concentrations of airborne respirable silica exceeded OELs by factors of 10, 20, or more, with Sand Mover and Transfer Belt Operators having the highest relative exposures. Although workers typically wore elastomeric half- mask, air-purifying (or filtering-facepiece style) respirators, due to the magnitude of the silica concentrations measured, half-masks may not be sufficiently protective because, in some cases, respirable crystalline silica concentrations exceeded the maximum use concentration (10 times the OEL) for that type of respirator.

Although effective engineering controls for crystalline silica are well established in other industries, controls to limit silica-containing dust generation during hydraulic fracturing are only now emerging due to the relatively recent understanding of the hazard and magnitude of exposure risks. Sand movers configured with some proposed controls (e.g., a minibaghouse retrofit assembly, skirting and shrouding at the base of the machine and on the dragon tail, and use of caps on fill ports) are described in Figures 1 and 2 in the online supplemental material discussing controls and recommendations. At one site (Bakken formation in North Dakota) substitution of a ceramic proppant for a portion of silica sand resulted in lower overall measured silica exposures, but assessing the technical and economic feasibility of using ceramic proppant was beyond the scope of this study.

\section{ACKNOWLEDGMENTS}

$\mathrm{W}$ e gratefully thank the oil and gas operators and completions companies - and especially their employees-for their demonstrated leadership in occupational health and safety by agreeing to participate in the NIOSH Field Effort to Assess Chemical Exposures in Oil and Gas Workers. We extend our deep gratitude to Rick Ingram (BP, Houston, Texas, and the National Service, Transmission, Exploration \& Production Safety [STEPS] Network) for his encouragement and support of the NIOSH Field Effort and his determined efforts organizing and moderating the 2012 Respirable Silica Focus Group, a recently organized effort involving the oil and gas industry, other related industries, NIOSH, and OSHA in collective discussions and actions toward rapid development and implementation of engineering, administrative, and personal protective equipment controls to increase awareness and protect completions crews from crystalline silica exposures.

In addition, we thank Kenneth Strunk, NIOSH Office of Mining Health and Safety Research, Spokane, Washington, for development of computer renderings of the NIOSH minibag house assembly and other controls; and Corey Campbell of the NIOSH Western States Office for her assistance with graphics.

We expressly recognize and thank Alan Echt, NIOSH Division of Applied Research and Technology; Jim Helmkamp of the NIOSH Western States Office; Dan Sharp of the NIOSH Health Effects Laboratory Division, Morgantown, West Virginia (detailed to NIOSH Western States Office); and Aaron Sussell, NIOSH, Division of Surveillance, Hazard Evaluations and Field Studies, for their reviews and thoughtful comments on preliminary drafts of the manuscript. 


\section{DISCLAIMER}

$\mathrm{T}$ he findings and conclusions in this report are those of the authors and do not necessarily represent the views of the National Institute for Occupational Safety and Health.

\section{REFERENCES}

1. Amandus, H., and J. Costello: Silicosis and lung cancer in U.S. metal miners. Arch. Environ. Health 46:82-89 (1991).

2. Steenland, K., and D. Brown: Silicosis among gold miners: Exposure-response analyses and risk assessment. Am. J. Public Health 85:1372-1377 (1995).

3. Hnizdo, E., and G.K. Sluis-Cremer: Silica exposure, silicosis, and lung cancer: A mortality study of South African gold miners. Br. J. Ind. Med. 48:53-60 (1991).

4. Centers for Disease Control and Prevention (CDC): Silicosis: Cluster in sandblasters - Texas and occupational surveillance for silicosis. MMWR 39(25):433-437 (1990).

5. Froines, J.R., D.H. Wegman, and C.A. Dellenbaugh: An approach to the characterization of silica exposure in U.S. industry. Am. J. Ind. Med. 10:345-361 (1986).

6. Landrigan, P.J., M.G. Cherniack, F.A. Lewis, L.R. Catlett, and R.W. Hornung: Silicosis in a grey iron foundry. The persistence of an ancient disease. Scand. J. Work Environ. Health 12(1):32-39 (1986).

7. Rosenman, K.D., M.J. Reilly, C. Rice, V. Hertzberg, C.Y. Tseng, and H.A. Anderson: Silicosis among foundry workers. Implication for the need to revise the OSHA standard. Am. J. Epidemiol. 144(9):890-900 (1996).

8. Echt, A., W. Sieber, A. Jones, and E. Jones: Control of silica exposure in construction: Scabbling concrete. Appl. Occup. Environ. Hyg. 17:809-813 (2002).

9. Echt, A., and W.K. Sieber: Control of silica exposure from hand tools in construction: Grinding concrete. Appl. Occup. Environ. Hyg. 17:457-461 (2002).

10. Petroleum Extension Service (PETEX): A Dictionary for the Oil and Gas Industry, First Edition. Austin, Texas: University of Texas at Austin, PETEX, 2005.

11. American Petroleum Institute (API): API RP 19C-Measurement of Proppants Used in Hydraulic Fracturing and Gravel-Packing Operations, First Edition. Washington, D.C.: API, 2008.

12. Centers for Disease Control and Prevention (CDC): "Fatalities Among Oil and Gas Extraction Workers, United States, 2003-2006." Available at http://www.cdc.gov/mmwr/preview/mmwrhtml $/ \mathrm{mm} 5716 \mathrm{a} 3 . \mathrm{htm}$ ?s_cid $=$ mm5716a3_e (accessed October 19, 2012).

13. Retzer, K.D., R.D. Hill, and G.A. Conway: Mortality Statistics for the U.S. Upstream Industry: An Analysis of Circumstances, Trends, and Recommendations. In Proceedings, SPE Americas E\&P Health, Safety, Security, and Environmental Conference, March 21-23, 2011, Houston, Texas. Society of Petroleum Engineers, 2011.

14. U.S. Department of Labor, Bureau of Labor Statistics (BLS): "Quarterly Census of Employment and Wages." Available at http://www. bls.gov/cew/ (accessed October 19, 2012).

15. National Institute for Occupational Safety and Health (NIOSH): "NIOSH Field Effort to Assess Chemical Exposures in Oil and Gas Workers." Available at www.cdc.gov/niosh/docs/2010-130/pdfs/2010-130.pdf (accessed June 10, 2012).

16. Nebergall, W.H., F.C. Schmidt, and H.F. Holtzclaw: General Chemistry, Fourth Edition. Lexington, Mass.: D.C. Heath and Co., 1972. p. 640 .
17. American Petroleum Institute (API): API/HF1, Hydraulic Fracturing Operations-Well Construction and Integrity Guidelines. Washington, D.C.: API, 2009.

18. American Petroleum Institute (API): API RP 56, Recommended Practices for Testing Sand Used in Hydraulic Fracturing Operations. Washington, D.C.: API, 1995.

19. Davis, G.S.: Silica. In Occupational and Environmental Respiratory Disease, First Edition, P. Harber, M.B. Schenker, and J.R. Balmes (eds.). St. Louis, Mo.: Mosby Year Book, Inc., 1996. pp. 373-399.

20. Castranova, V., D. Porter, L. Millecchia, J.Y.C. Ma, A.F. Hubbs, and A. Teass: Effect of inhaled crystalline silica in a rat model: Time course of pulmonary reactions. Mol. Cell. Biochem. 234/235:177-184 (2002).

21. Castranova V.: From coal mine dust to quartz: Mechanisms of pulmonary pathogenicity. Inhal. Toxicol. 12(Suppl 3):7-14 (2000).

22. Castranova, V., and V. Vallyathan: Silicosis and coal workers' pneumoniconiosis. Environ. Health Perspect. 108 (Suppl 4):675-684 (2000).

23. National Institute for Occupational Safety and Health (NIOSH): NIOSH Hazard Review: Health Effects of Occupational Exposure to Respirable Silica. DHHS (NIOSH) Pub. No. 2002-129. Cincinnati, Ohio: NIOSH, 2002.

24. National Toxicology Program (NTP): "12th Report on Carcinogens." Available at http://ntp.niehs.nih.gov/ntp/roc/twelfth/roc12.pdf (accessed June 10, 2012).

25. Rosenman, K.D., M.J. Reilly, and P.K. Henneberger: Estimating the total number of newly recognized silicosis cases in the United States. Am. J. Ind. Med. 44:141-147 (2003).

26. National Institute for Occupational Safety and Health (NIOSH): "Occupational Respiratory Disease Surveillance. National Occupational Respiratory Mortality System (NORMS)." Available at http://webappa.cdc.gov/ords/norms.html (accessed June 10, 2012)

27. National Institute for Occupational Safety and Health (NIOSH): "NIOSH Pocket Guide to Chemical Hazards." Available at http://www. cdc.gov/niosh/npg (accessed June 11, 2012).

28. ACGIH ${ }^{\mathbb{R}}: 2012$ TLVs and BEIs: Threshold Limit Values for Chemical Substances and Physical Agents and Biological Exposure Indices. Cincinnati, Ohio: ACGIH, 2012.

29. "Air Contaminants." Code of Federal Regulations Title 29, 1910.1000 2003.

30. Kenny, L.C., and R. Gussman: Characterization and modeling of a family of cyclone aerosol preseparators. J. Aerosol Sci. 28:677-688 (1996).

31. "Particulates not Otherwise Regulated, Respirable." Available at http:// www.cdc.gov/niosh/docs/2003-154/pdfs/0600.pdf (accessed October 19, 2012).

32. "Silica, Crystalline, by XRD (filter redeposition)." Available at http:// www.cdc.gov/niosh/docs/2003-154/pdfs/7500.pdf (accessed October 19, 2012).

33. Hornung, R.W., and L.D. Reed: Estimation of average concentration in the presence of nondetectable values. Appl. Occup. Environ. Hyg. 5:46-51 (1990).

34. Steele, R.G.D., and J.H. Torrie: Principles and Procedures of Statistics with Special Reference to the Biological Sciences. New York, N.Y.: McGraw-Hill, 1960. p. 106.

35. Shapiro, S.S., and M.B. Wilk: An analysis of variance test for normality. Biometrika 52:591-611 (1965).

36. Chambers, J.M., W.S. Cleveland, B. Kleiner, and P.A. Tukey: Graphical Methods for Data Analysis. Belmont, Calif.: Wadsworth International Group, 1983. 


\section{Online Supplement}

\section{"Controls and Recommendations to Limit Worker Exposures to Respirable Crystalline Silica at Hydraulic Fracturing Work Sites"}

\section{Engineering Controls}

Based on workplace observations of various points of dust release on sand movers, NIOSH developed two engineering controls, one at the conceptual stage and one at the proof of concept stage. The first is a series of mini-bag houses that attach to the rim of a sand mover thief hatch and exploits positive pressure generated in the sand bins by the air compressor on the sand refill truck. Dust control is achieved as a filter cake develops on the inside of the bag house fabric. The design is intended to be self-cleaning as the filter cake is sloughed as the bag house fabric expands and collapses as air pressure is pulsed at the end of bin filling. This design is intended to be a "bolt-on" retrofit control option for sand movers currently operating in the field, but also could be configured in as part of original equipment manufacturer (OEM) for new models of sand movers. Figures 1 and 2 illustrate the concept of the mini-baghouse retrofit. A second control (at the conceptual stage) is a screw auger retrofit assembly to replace the sand belt on sand mover. This control requires more extensive engineering and mechanical retrofitting to existing sand movers, but could also be included in new OEM models.

An additional active control (which may currently be in production) includes use of a hood and ductwork connected to sand mover thief hatch openings connecting to a central manifold and then to a stand-alone baghouse for dust collection. Other (passive) considerations include enclosures, specifically installation of skirting or stilling curtains along the sides of the sand mover to contain particulate emissions from the sand belt. Similarly, enclosures and shrouding can be considered along the dragon 
tail with shrouding at the end of the dragon tail to limit dust emissions at the interface of transfer belts and blender hoppers. Keeping the dragon tail as close to the blender hopper or transfer belt to minimize the distance the proppant falls can reduce dust generation. Mandating the use of end caps on fill ports of sand movers is a simple and cost effective way to control silica dust ejected from this point source. Using dust control (magnesium or chloride amended water) on lease roads and at the well pad area can reduce on-site dust generation. The use of well brines is not recommended as these may contain naturally occurring radioactive materials (NORM), including isotopes of Uranium, Thorium, Radium.

\section{NIOSH recently published Best Practices for Dust Control in Metal/Nonmetal Mining (NIOSH}

Informational Circular 9521) which discusses dust control in underground mining operations. ${ }^{(1)}$ Results from this document have direct relevance in hydraulic fracturing operations. Dust suppression using water misting may be acceptable and effective if misting nozzles are located in the correct locations and fine spray, atomizing nozzles are used. A recent paper found that the use of water spray application reduced respirable silica concentrations by $69-82 \%$ in outside stone crushing mills. ${ }^{(2)}$

While this study involved a systematic approach to understanding risks for work crew exposures to respirable crystalline silica, and is believed to be substantially representative, it may not address all points of dust generation or all options for effective controls.

\section{Personal Protective Equipment}

Until a variety of engineering or other controls can be conceived, developed, evaluated and confirmed to be effective for controlling respirable silica exposures to hydraulic fracturing work crews, the use of respiratory protection will be required. NIOSH approved, air-purifying, elastomeric half masks and filtering-facepiece respirators with particulate efficiencies of N-95 and greater are recommended as a minimum protection when PBZ exposures can be confirmed to be less than 10 times the relevant OELs. Because some PBZ samples exceeded either the OSHA calculated PELs or the 
NIOSH REL by a factor of 10 or more [the maximum use concentration (MUC) for that type of respirator], full-face, air-purifying respirators which are assigned a protection factor of 50 may need to be used in some cases. Considering the NIOSH REL of $0.05 \mathrm{mg} / \mathrm{m}^{3}$ as a TWA, the MUC for a half face respirator would be an airborne concentration of respirable silica equivalent to $0.5 \mathrm{mg} / \mathrm{m}^{3}$ as a TWA. In this study, respirable silica concentrations among Sand Mover and T-belt Operators notably exceeded this concentration, especially for Sand Mover Operators.

\section{RECOMMENDATIONS}

Conducting workplace exposure assessments to characterize work crew exposures to respirable crystalline silica is a recommended first step in understanding the scope of controls that may be needed. Employers should conduct full-shift worker exposure assessments, unless a decision is made to immediately implement controls and then reevaluate the degree of exposure hazard based on use of controls. Since silica-containing dusts are generated from multiple locations, multiple types of controls (active and passive engineering controls, administrative and PPE) will be needed to prevent or mitigate workplace exposures.

Worker exposures to respirable crystalline silica should be controlled to the lowest concentrations achievable, certainly below calculated OSHA PELs and ideally below the NIOSH REL. Employers with workers at hydraulic fracturing worksites should focus on the traditional industrial hygiene hierarchy of controls, specifically: eliminate the hazard if possible and substitute less toxic proppant where feasible. Because engineering controls may not be completely effective, employers are encouraged to ensure that an effective respiratory protection program is in place that meets the criteria of the OSHA Respiratory

Protection Standard (29 CFR 1910. 134). ${ }^{(2)}$ and consult OSHA Directive CPL 03-00-007, National Emphasis Program-Crystalline Silica, for detailed information on silica hazards, guidelines for air 
sampling, guidance on calculating PELs for respirable dust containing silica, and other compliance information. $^{(3)}$

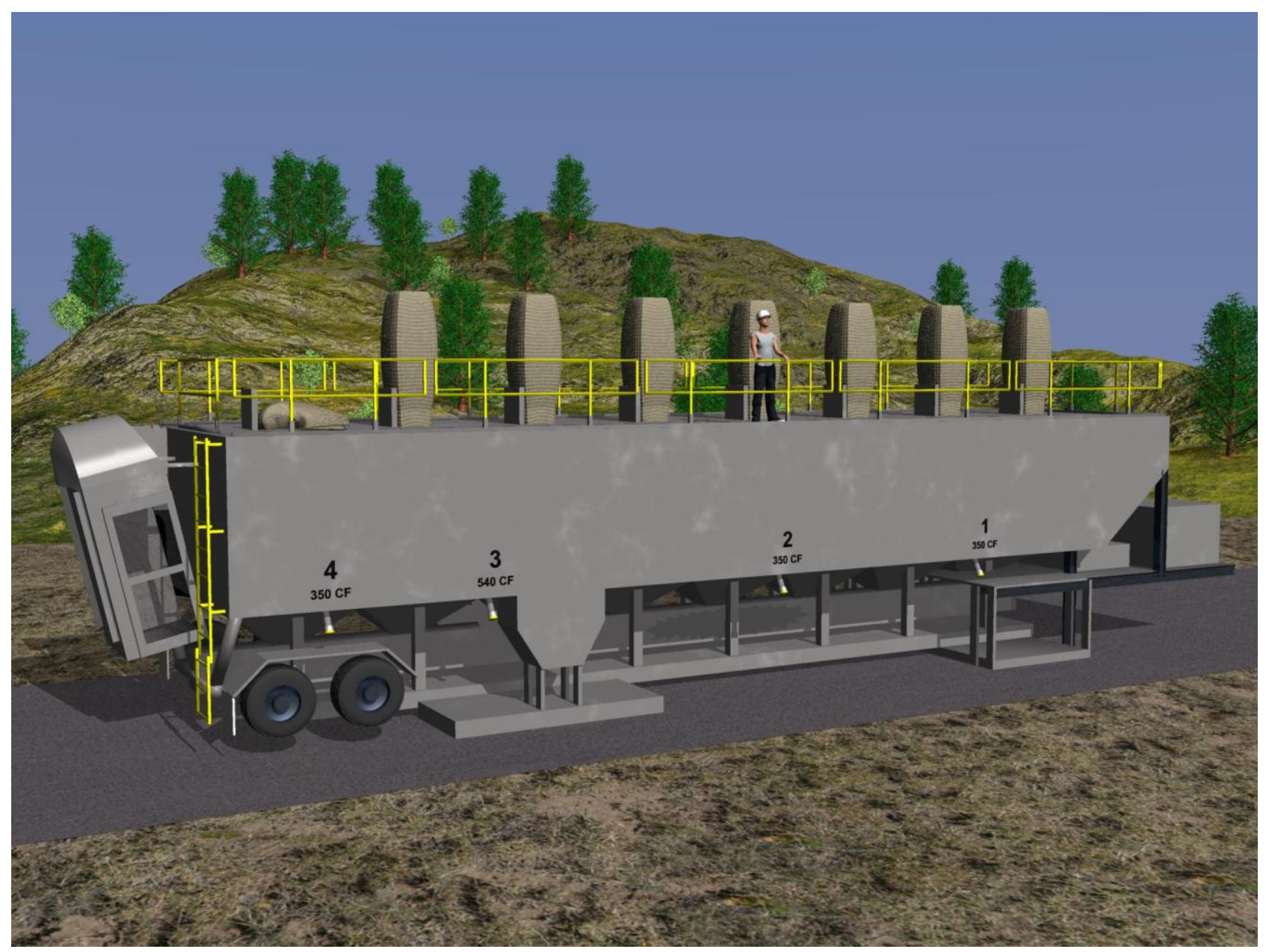

FIGURE 1. Conceptual rendering of seven NIOSH mini bag house retrofit assemblies in place on a sand mover. Note the presence of fill port caps (in place) on the four fill nozzles below sand bins to control release of dust from this source and enclosure around dragon tail (far left side of sand mover). 


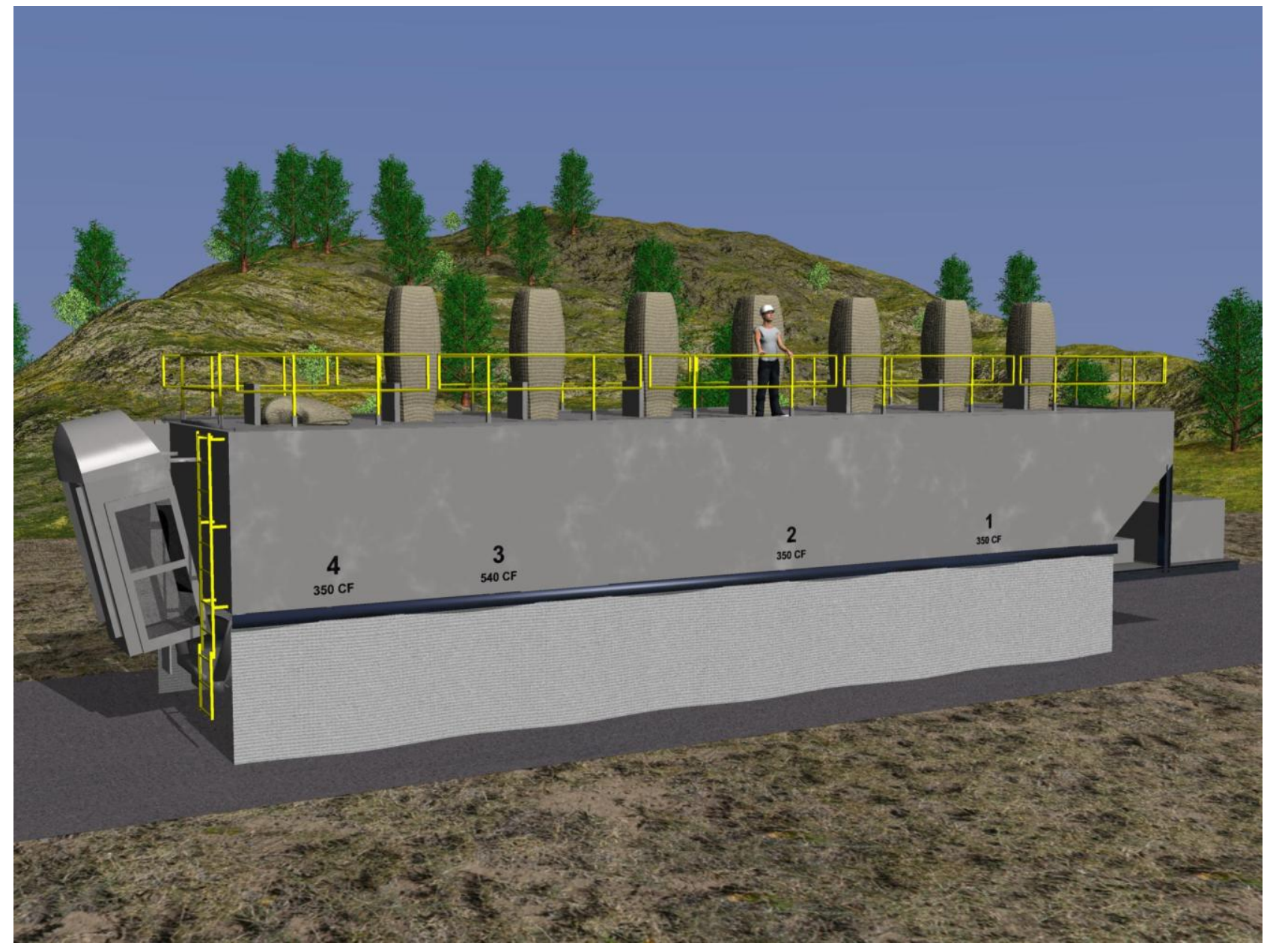

FIGURE 2. Conceptual rendering of staging/stilling curtains in place to control dust emissions from sand mover belt and enclosure around dragon tail. 


\section{REFERENCES}

${ }^{1}$ NIOSH: Best Practices for Dust Control in Metal/Nonmetal Mining. U.S. Department of Health and Human Services, Centers for Disease Control and Prevention, National Institute for Occupational Safety and Health, DHHS (NIOSH). Information Circular 9521. Publication No. 2010-132 (2012).

${ }^{2}$ U.S. Department of Labor, OSHA: CFR 1910.134. Personal Protective Equipment. Respiratory Protection. http://www.osha.gov/pls/oshaweb/owadisp.show_document?p_id=12716\&p_table=standards Date accessed: January 25, 2013.

${ }^{3}$ U.S. Department of Labor, OSHA: OSHA Instruction, National Emphasis Program-Crystalline Silica http://www.osha.gov/pls/oshaweb/owadisp.show_document?p_table=DIRECTIVES\&p_id=3790

Date accessed: January 25, 2013.

“Occupational Exposures to Respirable Crystalline Silica During Hydraulic Fracturing"

By Eric J. Esswein ${ }^{1}$, Michael Breitenstein ${ }^{2}$, John Snawder ${ }^{2}$, Max Kiefer $^{1}$ and Karl Sieber ${ }^{3}$

${ }^{1}$ National Institute for Occupational Safety and Health (NIOSH), Western States Office, Denver, Colorado ${ }^{2} \mathrm{NIOSH}$, Division of Applied Research and Technology, Cincinnati, Ohio

${ }^{3} \mathrm{NIOSH}$, Division of Surveillance, Hazard Evaluations and Field Studies, Cincinnati, Ohio

Journal of Occupational and Environmental Hygiene - July 2013 